\title{
The Nanostructured CuO Films in The Different Thermal Oxidation Mediums: Production and XRD, UV-vis-NIR, FESEM and Raman Investigations
}

\author{
Olcay Gençyılmaz ${ }^{1 *}$ \\ 1* Çankırı Karatekin University, Çerkeş Vocational School, Department of Materials and Material Processing Technologies, Çankırı, Türkiye, \\ (ORCID: 0000-0002-7410-2937), ogencyilmaz@karatekin.edu.tr
}

(International Conference on Design, Research and Development (RDCONF) 2021 - 15-18 December 2021)

(DOI: 10.31590/ejosat.1040788)

\begin{abstract}
ATIF/REFERENCE: Gençyılmaz, O., (2021). The Nanostructured CuO Films in The Different Thermal Oxidation Mediums:
\end{abstract} Production and XRD, UV-vis-NIR, FESEM and Raman Investigations. European Journal of Science and Technology, (32), 248-256.

\begin{abstract}
In this work, $\mathrm{CuO}$ films were produced by the successive ionic layer adsorption and reaction (SILAR) method. The oxidation process was applied to $\mathrm{CuO}$ films in three different mediums as air, oxygen and argon. $\mathrm{CuO}$ films were kept at $400{ }^{\circ} \mathrm{C}$ for 2 hours in each medium during the oxidation process. The effect of the selected medium in the oxidation process on the physical properties of the $\mathrm{CuO}$ films was investigated. This study showed that the physical properties of the $\mathrm{CuO}$ films can vary significantly in different oxidation mediums. XRD studies reveal that all the films are polycrystalline with monoclinic structure and exhibit (-111) and (111) preferential orientations. Grain sizes were determined to vary in the range of $26-28 \mathrm{~nm}$ in different oxidation mediums. The XRD results were confirmed by Raman spectrum analysis. The band gap values increased between from 1.80 to $2.11 \mathrm{eV}$. In addition, it was discovered that with the oxidation of $\mathrm{CuO}$ films in argon medium, crystalline melanothallite structure was formed and the surface morphology was significantly changed.
\end{abstract}

Keywords: $\mathrm{CuO}$ nanostructure, Thermal oxidation, Melanothallite structure, XRD, RAMAN, FESEM.

\section{Farklı Termal Oksidasyon Ortamlarında Nanoyapılı CuO Filmler: Üretim ve XRD, UV-NIR, FESEM ve Raman Araştırmaları}

$\ddot{O} z$

$\mathrm{Bu}$ çalı̧̧mada, $\mathrm{CuO}$ filmleri ardışık iyonik tabaka adsorpsiyonu ve reaksiyonu (SILAR) yöntemiyle üretilmiştir. CuO filmlerine hava, oksijen ve argon olmak üzere üç farklı ortamda oksidasyon işlemi uygulanmıştır. Oksidasyon işlemi sırasında $\mathrm{CuO}$ filmleri her ortamda $400{ }^{\circ} \mathrm{C}^{\prime}$ de 2 saat tutulmuştur. $\mathrm{CuO}$ filmlerinin oksidasyon işleminde seçilen ortamın filmlerin fiziksel özellikleri üzerindeki etkisi araştırılmıştır. $\mathrm{Bu}$ çalışma, $\mathrm{CuO}$ filmlerinin fiziksel özelliklerinin farklı oksidasyon ortamlarında önemli ölçüde değişebileceğini göstermiş̧ir. XRD çalışmaları, tüm filmlerin monoklinik yapıya sahip polikristal olduğunu ve (-111) ve (111) tercihli yönelimler sergilediğini ortaya koymaktadır. Tane boyutlarının farklı oksidasyon ortamlarında $26-28 \mathrm{~nm}$ aralığında değiştiği belirlenmiştir. XRD sonuçları Raman spektrum analizi ile doğrulanmıştır. Bant aralığı değerleri 1.80'den 2.11 eV'ye yükselmiştir. Ayrıca $\mathrm{CuO}$ filmlerinin argon ortamında oksidasyonu ile kristal melanothallit yapısının oluştuğu ve yüzey morfolojisinin önemli ölçüde değiştiği keşfedilmiştir.

Anahtar Kelimeler: CuO nanoyapılar, Termal oksidasyon, Melanotalit yapı, XRD, RAMAN, FESEM.

\footnotetext{
*Corresponding Author: ogencyilmaz@karatekin.edu.tr
} 


\section{Introduction}

Copper oxide $(\mathrm{CuO})$ is a p-type transition metal oxide semiconductor with a narrow band gap $\left(\mathrm{E}_{\mathrm{g}}=1.2\right.$ to $\left.2.2 \mathrm{eV}\right) . \mathrm{CuO}$ has a monoclinic crystal structure and the two stable oxide forms as $\mathrm{CuO}$ (tenorite) and $\mathrm{Cu} 2 \mathrm{O}$ (cuprite) (Johan vd., 2011; Serin vd., 2005; Akgül vd., 2014). It has been widely investigated for various applications due to its physical properties such as nontoxicity, great chemical stability, abundance in nature, costeffective synthesis, high surface area, good electrochemical activity, suitable redox potential (Ahmad vd., 2015). As semiconductor, these physical properties make it an advantageous and promising material for various device applications including in gas sensors, biosensors, solar energy transformation, catalysis, batteries, solar energy transformation and high-temperature superconductors (Sangwaranatee vd., 2018; Verma vd., 2012; Zou vd., 2011; Umar vd., 2009; Kuamr vd., 2013; Heng vd., 2015).

There are several chemical and physical techniques (sputtering, electrodeposition, thermal evaporation, chemical vapor deposition, sol-gel, chemical bath deposition and successive ionic layer adsorption and reaction (SILAR) etc.) to produce $\mathrm{CuO}$ films (Nednorz vd., 1986; Mukherjee vd., 2011; Jin vd.; 2012; Koh vd., 2013; Qin vd., 2012; Bayansal vd., 2012). SILAR is a liquid-phase chemical deposition method which has various advantages such as low cost, layer-by-layer growing feature, well suitability, low deposition temperature, good reproducibility, high feasibility for large area deposition, low deposition time. Also, it has good control over film thickness efficiency compared the other chemical techniques.

Despite extensive studies that have been done on the deposition and characterization of $\mathrm{CuO}$ films, the effect of the oxidation medium on the physical properties of films is still poorly examined. As one of the few works, Halin et al. (Halin vd., 2014) discussed the effect of nitrogen and air mediums on the microstructure and phases of $\mathrm{CuO}$ films prepared by the sol-gel method (Bayansal vd., 2014). Most studies are related to the oxidation temperature and duration (Saad vd., 2020; Özaslan vd., 2020; Singh vd., 2019). To our knowledge, there is no study about the effect of the oxidation medium on the physical properties of $\mathrm{CuO}$ films deposited by the SILAR method. Therefore, we have been determined the effect of the oxidation medium on the some physical properties such as structural, morphological and optical properties of $\mathrm{CuO}$ films.

\section{Material and Method}

\subsection{Production of $\mathrm{CuO}$ Films}

$\mathrm{CuO}$ films were deposited on nonconductive microscope glass by the SILAR method. Before the deposition, the glass substrates were cleaned as reported elsewhere (Shevko vd., 2015; Gençyılmaz vd., 2017). CuO films were deposited as follows: First, $0.3 \mathrm{M}$ copper chloride solution was prepared with $\mathrm{CuCl}_{2} \cdot 2 \mathrm{H}_{2} \mathrm{O}$. Doubly distilled water was used as the solvent, and aqueous ammonia was added to the starting solution to adjust the value of $\mathrm{pH}=9.5$. In our previous study, it was determined that the $\mathrm{pH}=9.5$ value was appropriate for the production of $\mathrm{CuO}$ films by the SILAR method. Therefore, in this study, the thermal oxidation effect was investigated by producing $\mathrm{CuO}$ films at $\mathrm{pH}=9.5$ (Gençyılmaz vd., 2017). Then, the solution was heated up to $90^{\circ} \mathrm{C}$.
During the experiments, the temperature was kept as constant. A SILAR cycle can be described as follows:

The substrates were dipped into the solution containing $\mathrm{Cu}^{2+}$ ions and kept there for $20 \mathrm{~s}$. Then, they were taken out of the bath and immersed in hot water for $20 \mathrm{~s}$. And then they left in $90{ }^{\circ} \mathrm{C}$ air for $20 \mathrm{~s}$ to dry. This completes one cycle of film formation. This cycle was repeated 10 times until the desired thickness is reached. Finally, as-deposited films were oxidized at $400{ }^{\circ} \mathrm{C}$ for $2 \mathrm{~h}$ in air, oxygen and argon mediums separately using PTF 12/38/250 model Protherm tube furnace. Also, the experimental processing of SILAR and photographs of deposited films are shown in Fig. 1 and Fig. 2, respectively.

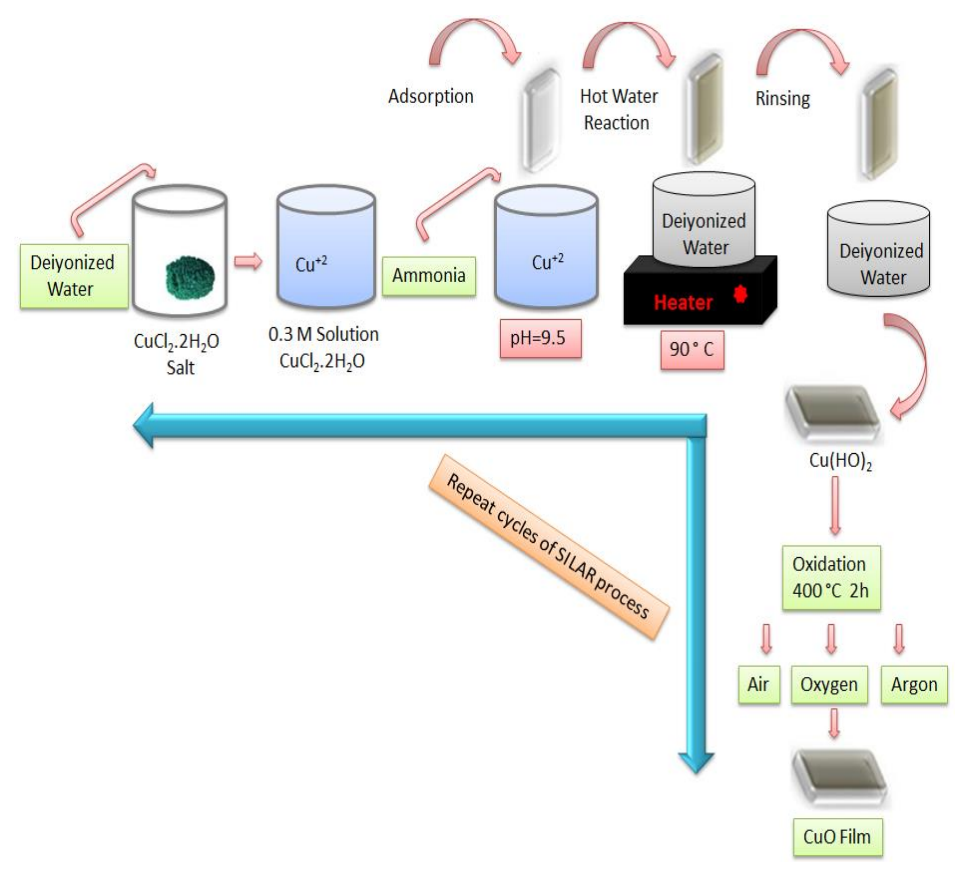

Figure 1. The experimental process (SILAR) of CuO films
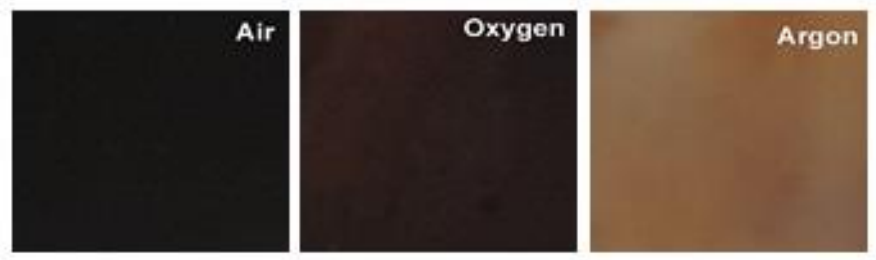

Figure 2. The photographs of $\mathrm{CuO}$ films

\subsection{Characterization of $\mathrm{CuO}$ Films}

All characterizations of $\mathrm{CuO}$ films were performed at room temperature. X-ray diffractometer (Bruker D8 Advance XRD) with $\mathrm{CuK}_{\alpha}$ line $(\lambda=1.5406 \AA)$ was used to analyze the crystal structure. The morphological structure of films were investigated by a field emission scanning electron microscopy (FESEM Zeiss Ultra Plus). The thickness of $\mathrm{CuO}$ films was calculated by the weighing method using Ohaus-Pioneer digital the weighing balance. The thickness was calculated using the formula:

$$
T=\frac{\Delta W}{\rho l b}
$$


where $T$ is film thickness, $\Delta W$ is the difference in weight of substrate before and after film deposition, $\rho$ is the density of the film as gr. $\mathrm{cm}^{-3}, l$ and $b$ are the bare length and breadth of the substrate, respectively. The thicknesses of the $\mathrm{CuO}$ films were determined by the weighing method and given in Table 2 . The optical properties and band gap of the films was evaluated from the transmission measurements recorded using a Rayleigh UV2601 double beam UV/VIS spectrophotometer in the wavelength range 200-1100 nm. Raman spectra were obtained with a Bruker Senterra Dispersive Raman Microscope. A 3B diode laser (785 $\mathrm{nm}$ ) having $3-5 \mathrm{~cm}^{-1}$ resolution was used as an excitation source at a power of $25 \mathrm{~mW}$.

\section{Results and Discussion}

\subsection{Structural Characterization}

XRD results show that as-deposited films grown onto the glass substrates present good crystallinity (Fig. 3). All diffraction peaks could be finely indexed to an orthorhombic, (Pnam (62)) phase with diffraction peaks at (001), (110), (201), (202), and (203) (Atacamite, JCPDS 25-0269). The average grain size of the as-deposited film is calculated to be $14 \mathrm{~nm}$ for the (100) peak using the Scherrer's formula. Atacamite $\left(\mathrm{Cu}_{2} \mathrm{Cl}(\mathrm{OH})_{3}\right)$ is not a stable compound which decomposes at a temperature higher than $215{ }^{\circ} \mathrm{C}$ with the possible formation of $\mathrm{CuCl}, \mathrm{CuCl}_{2}, \mathrm{Cu}_{3} \mathrm{Cl}_{3}$, $\mathrm{Cu}_{4} \mathrm{Cl}_{4}, \mathrm{CuO}, \mathrm{H}_{2} \mathrm{O}, \mathrm{HCl}, \mathrm{O}_{2}$. The deposition mechanism is given below:

$$
2 \mathrm{Cu}_{2} \mathrm{Cl} .(\mathrm{OH})_{3}=\mathrm{CuCl}_{2}+3 \mathrm{CuO}+3 \mathrm{H}_{2} \mathrm{O}
$$

Complete chlorination $(99.92 \%)$ is marked at $1500{ }^{\circ} \mathrm{C}$ (Zamfirescu vd., 2010). Since annealing the glass substrate would be impossible above $600{ }^{\circ} \mathrm{C}$, the $\mathrm{Cl}$ atoms will exist anyway in the structure after the oxidation process. After oxidation at $400{ }^{\circ} \mathrm{C}$ for $2 \mathrm{~h}$ in air, oxygen and argon mediums, as deposited films converted to $\mathrm{CuO}$ films (Fig. 3). X-ray diffraction patterns show that the annealed $\mathrm{CuO}$ films in air and oxygen atmospheres comparatively present high crystallinity. All (110), (-111), (111) (202), (020), (202), (- 113), (- 311), (220), and (-222) diffraction peaks can be clearly indexed to the monoclinic $\mathrm{CuO}$ phase with lattice constants of $a=4.684 \AA, b=3.425 \AA, c=5.129 \AA$ (Tenorite, JCSPD 05-0661). For $\mathrm{CuO}$ films, oxidation in the argon medium caused a clear change in the crystalline structure. In the XRD pattern of the oxidized film in argon medium, an additional diffraction peak located at $\quad 2 \theta=31.750^{\circ}$ was observed (Fig. 3). This diffraction peak could not be determined as belonging to the copper oxide formation. In the literature, similar results were obtained in studies on the production and characterization of $\mathrm{CuO}$ films (Yüksel vd., 2020; Çavuşoğlu vd., 2019; Zgaira vd., 2019; Daoudi vd., 2019).

On the other hand, this diffraction peak well fits to melanothallite $\left(\mathrm{Cu}_{2} \mathrm{OCl}_{2}\right)$ structure (JCSPD 35-0679) which is a naturally occurring mineral known as part of the category of oxyhalogenides. It has an orthorhombic, dipyramidal crystalline structure with interlaced atoms of copper, chlorine, and oxygen. Fig. 4 shows the chains of $\mathrm{Cu}^{2+}$ ions linked by $\mathrm{O}$ and $\mathrm{Cl}$ bridges in the structure of $\mathrm{Cu}_{2} \mathrm{OCl}_{2}$. This structure is symmetric and it has independent $\mathrm{Cu}^{2+}$ ion and interconnected by two $\mathrm{O}$ and four $\mathrm{Cl}$ atoms. Since $\mathrm{Cu}_{2} \mathrm{OCl}_{2}$ decomposes into $\mathrm{CuO}$ (tenorite) and $\mathrm{CuCl}_{2}$ at about $400{ }^{\circ} \mathrm{C}$, no peaks regarding $\mathrm{Cu}_{2} \mathrm{OCl}_{2}$ were seen in XRD patterns of oxidized films in air and oxygen (Anthony, 1997). This phase is described as the temperature in literature. Generally, this phase was found $\sim 300{ }^{\circ} \mathrm{C}$ in air and has been transformed into copper oxide at high temperatures as $\sim 500{ }^{\circ} \mathrm{C}$ (Centi vd., 1989). Although the oxidation temperature $\left(400{ }^{\circ} \mathrm{C}\right)$ did not change in our work, the films which are oxidized in different medium exhibited the melanothallite $\left(\mathrm{Cu}_{2} \mathrm{OCl}_{2}\right)$ phase.

Figure 3. XRD patterns of $\mathrm{CuO}$ films (a) as-deposited and
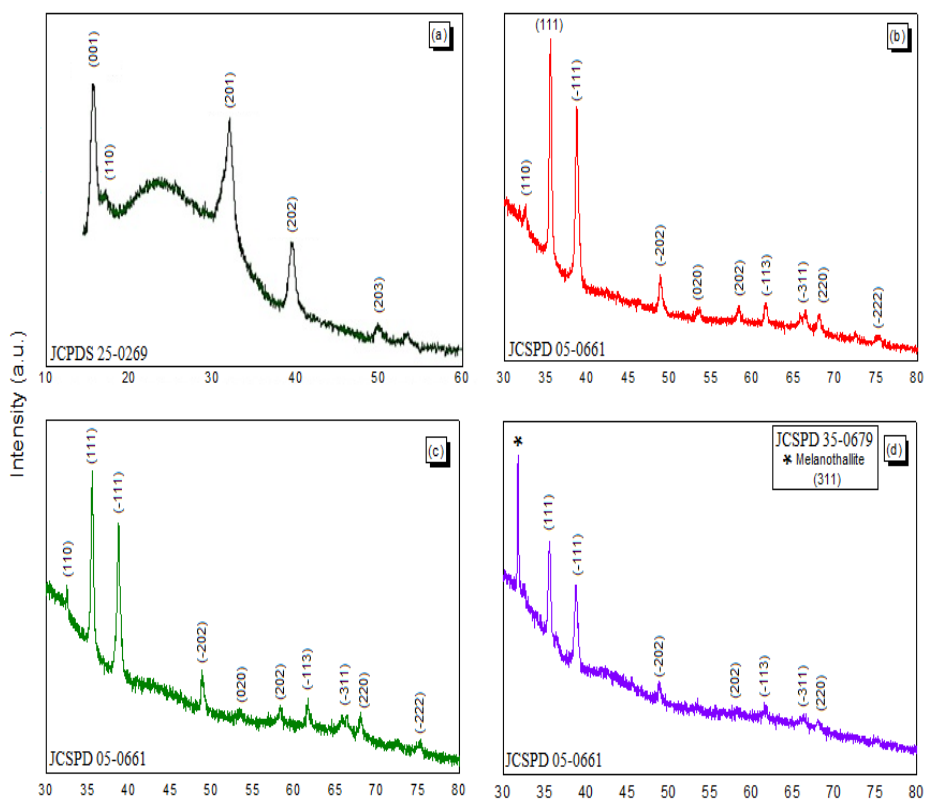

$2 \theta\left(^{\circ}\right)$

oxidized in (b) air, (c) oxygen and (d) argon mediums

The existence of $\mathrm{Cl}$ is clearly seen in the XRD pattern of the asdeposited film. The oxidation process in air and oxygen supports the formation of $\mathrm{CuO}$. We think that the $\mathrm{Cl}$ atoms were located at the grain boundaries and oxidation in the argon medium may have induced $\mathrm{Cl}$ atoms in surface accumulation. In this way, $\mathrm{Cl}$ atoms combined with $\mathrm{CuO}$ molecules and substitute melanothallite $\left(\mathrm{Cu}_{2} \mathrm{OCl}_{2}\right)$ lattice. Oxidation in the argon medium, in a deficiency of oxygen, $\mathrm{Cl}$ atoms may have a chance to link to the $\mathrm{CuO}$ molecules to form the melanothallite.

The new formation mechanism is given below:

$\mathrm{Cu}_{2} \mathrm{O}+\mathrm{Cl}_{2} \rightarrow \mathrm{Cu}_{2} \mathrm{OCl}_{2}$

Under the Argon medium, the partial vapor pressure of the elements that make up the film is lower and the probability of evaporation is reduced. Therefore, $\mathrm{Cl}$ atoms could not evaporate in argon medium and formed this phase $\mathrm{O}$ and $\mathrm{Cl}$ bridges in the structure of melanothallite (Qin vd., 2010).

The texture coefficient was calculated using the following equation using the XRD data (Mahr vd., 1962):

$T C=\frac{I_{(h k l)} / I_{0(h k l)}}{\frac{1}{N} \sum_{N} I_{(h k l)} / I_{0(h k l)}}$

where $I_{(h k l)}$ is the measured intensity, $\mathrm{I}_{0(h k l)}$ is the standard intensity, and $N$ is the number of diffraction peaks. For a preferential orientation, the $\mathrm{TC}_{(h k l)}$ values should be greater than one (Qin vd., 2010). It was determined that the dominant orientations of the films (111), (-111) and (-202) were in line. The change of $\mathrm{TC}_{(h k l)}$ values calculated for each dominant orientation and values are given in Figure 5 and Table 1. From the investigation of $\mathrm{TC}_{(h k l)}$ values, it can be distinctly seen that (-111) plane is the preferential plane for all oxidized $\mathrm{CuO}$ films. 


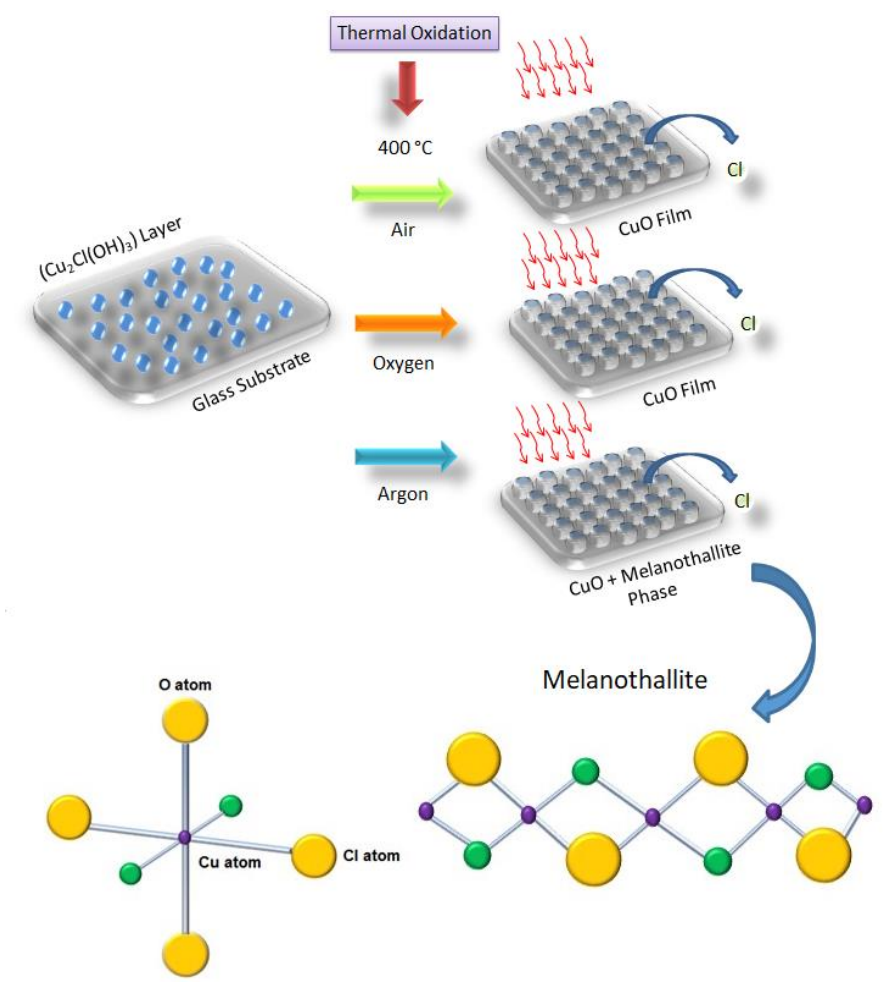

Figure 4. Schematic representation of the oxidation state of $\mathrm{CuO}$ films in different mediums and the chains of $\mathrm{Cu}^{2+}$ ions linked by $O$ and $\mathrm{Cl}$ bridges in the structure of melanothallite (Qin vd., 2010)

The average grain size of $\mathrm{CuO}$ was estimated from X-ray line broadening for (-111) plane using the Scherrer formula (Mahr, 1962):

$$
D=\frac{0.9 \lambda}{\beta \cos \theta}
$$

where $\beta$ is the broadening of the diffraction line measured at half of its maximum intensity (FWHM) and $\lambda$ is the wavelength of Xray radiation $(1.5406 \AA)$.

The strain values were calculated from the following relation (Dhaouadi vd., 2019):

$$
\varepsilon=\frac{\beta}{4 \operatorname{tang}(\theta)}
$$

No significant change is seen in grain size and strain values with the chancing of the oxidation medium (Table 1). The grain sizes have been calculated from the FWHM of the (111) peaks that are shown in Fig. 6. The values of grain size are found to decrease from 27.9 to $26.9 \mathrm{~nm}$ with a chancing oxidation medium. Additionally, dislocation density can be calculated using the relation $(7)$ :

$$
\delta=\frac{1}{D^{2}}
$$

where $D$ is crystallite size. While the crystalline dislocation intensity increases in oxygen medium, it is almost the same in air and argon medium.

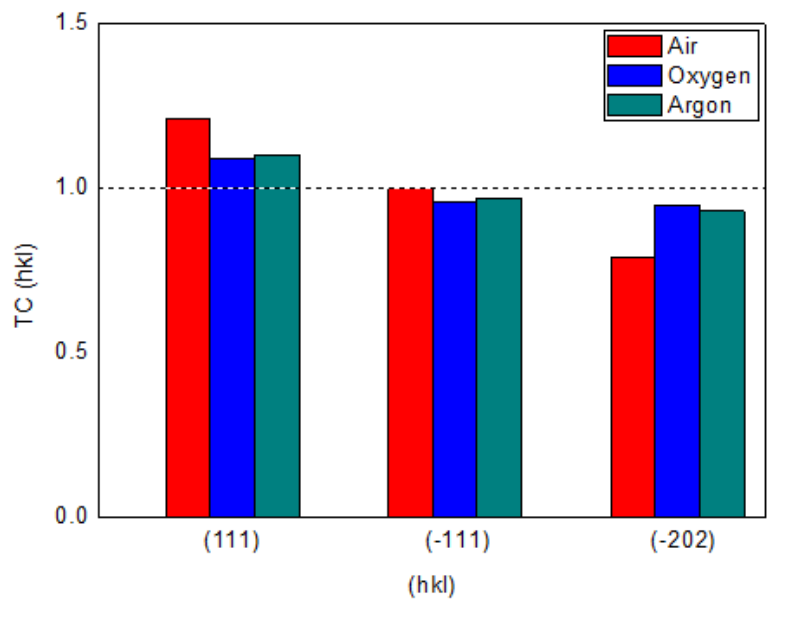

Figure 5. $T C_{(h k l)}$ change of CuO films as a function of oxidation medium

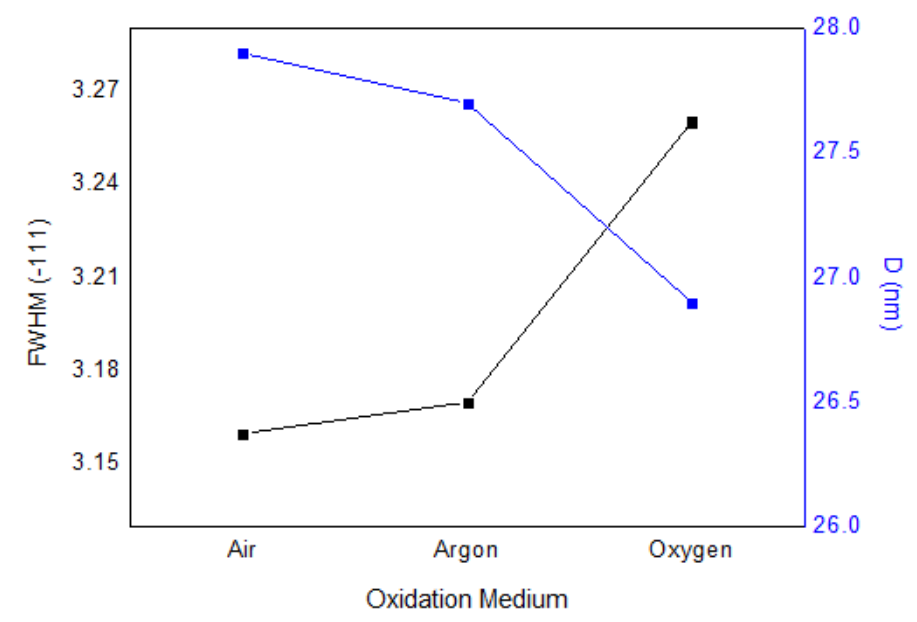

\begin{tabular}{|c|c|c|c|c|}
\hline \multirow{2}{*}{\multicolumn{2}{|c|}{ CuO Films }} & \multicolumn{3}{|c|}{ Oxidation Mediums } \\
\hline & & Air & Oxygen & Argon \\
\hline \multicolumn{2}{|c|}{ FWHM (-111) } & 0.316 & 0.326 & 0.317 \\
\hline \multicolumn{2}{|l|}{$D(\mathbf{n m})$} & 27.9 & 26.9 & 27.7 \\
\hline \multirow{3}{*}{$\mathbf{T C}(h k l)$} & $(-111)$ & 1.21 & 1.09 & 1.10 \\
\hline & $(111)$ & 1.00 & 0.96 & 0.97 \\
\hline & $(-202)$ & 0.79 & 0.95 & 0.93 \\
\hline \multicolumn{2}{|c|}{$\delta\left(\mathrm{nm}^{2}\right) \times 10^{-3}$} & 1.28 & 1.38 & 1.30 \\
\hline \multicolumn{2}{|c|}{$A_{g} \operatorname{mode}\left(\mathrm{cm}^{-1}\right)$} & 296 & 296 & 298 \\
\hline
\end{tabular}

Figure 6. FWHM and grain size change of $\mathrm{CuO}$ films

Table 1. The structural parameters of CuO films 


\subsection{Raman characterization}

The Raman spectra of $\mathrm{CuO}$ films, annealed in air, argon and oxygen mediums are shown Fig. 7. In Fig. 7, Raman peaks were observed at $296 \mathrm{~cm}^{-1}, 338 \mathrm{~cm}^{-1}$ and $612 \mathrm{~cm}^{-1}$ wavelength which are cupric oxide monoclinic structure and belong to $\mathrm{C} 2$ /c group symmetry. There are 12 zone center optical phonon modes, $4 \mathrm{~A}_{\mathrm{u}}+$ $5 \mathrm{~B}_{\mathrm{u}}+\mathrm{A}_{\mathrm{g}}+2 \mathrm{~B}_{\mathrm{g}}$, three of which $\mathrm{A}_{\mathrm{g}}+2 \mathrm{~B}_{\mathrm{g}}$ are the Raman active modes. The peak at $296 \mathrm{~cm}^{-1}$ is assigned to $\mathrm{A}_{\mathrm{g}}$ phonon modes. The two peaks at $338 \mathrm{~cm}^{-1}$ and $612 \mathrm{~cm}^{-1}$ could are assigned to two $\mathrm{B}_{\mathrm{g}}$ modes. The peak at $426 \mathrm{~cm}^{-1}$ was assigned to two phonons mode (Saad vd., 2020). It is also obvious that the $\mathrm{A}_{\mathrm{g}}$ mode has blue-shift in Raman spectra of the oxidized film in argon which may be attributed to surface morphology and the defects or impurity atoms in the $\mathrm{CuO}$ crystal structure (Halin vd., 2014).

The change in morphology and the structure also saw in SEM and XRD analysis and also the $\mathrm{CuO}$ phase formation in Raman spectra were confirmed by XRD data. Also, a measurable expansion of the Raman lines was detected in Fig. 7. This may be since the fact that the crystallization level of the films is better, especially in air and argon mediums. Similar results are available in the literature (Dhaouadi vd., 2019; Moumen vd., 2019; Djebian vd., 2020; Peng vd, 2021).

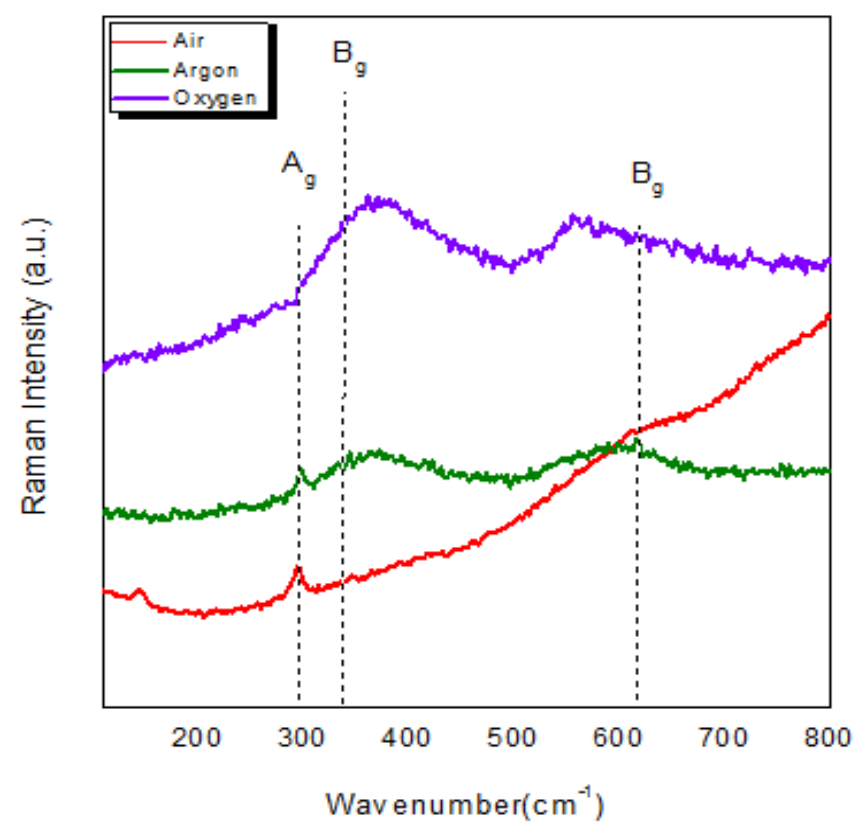

Figure 7. Raman spectra of the $\mathrm{CuO}$ films oxidized under air, oxygen and argon mediums

\subsection{Surface Morphology Characterization}

For the morphological examination, a field emission scanning electron microscope (FESEM) was used. FESEM images were taken with In-Lens detector under $20 \mathrm{kV}$ operating voltage. All films were coated with $\mathrm{Au}$ utilizing an EMS sputter coater to dismiss the charging effect. The FESEM images of the surface morphologies of as-deposited and oxidized films were given in Fig. 8. From the FESEM images, all films seem compact and adhered well to the substrates with homogeneous surface morphology. It is seen that the oxidation under different mediums leads to the recrystallization of the film surface with the new shape and grain size. It was observed that a homogeneous and hard structure has been formed on the surface during the deposition of the films. With oxidation in the air medium, the e-ISSN: 2148-2683 structures on the surface became more granular, the harder structure began to deteriorate and turned into a cauliflower like structure with the change of oxidation medium. In oxidation in the oxygen medium, it showed surface properties similar to that of the air. However, the particle sizes on the surfaces of the films oxidized in oxygen medium are smaller than in the air medium. The most diversified surface structure has been obtained by oxidation in argon medium. Here, the particle size on the surface of the film has shrunk significantly and the intergranular gaps have increased. Similar surface effects have been observed in different studies in the literature (Zgaira vd., 2019; Daoudi vd., 2019; Bayansal vd., 2014; Peng vd., 2021).

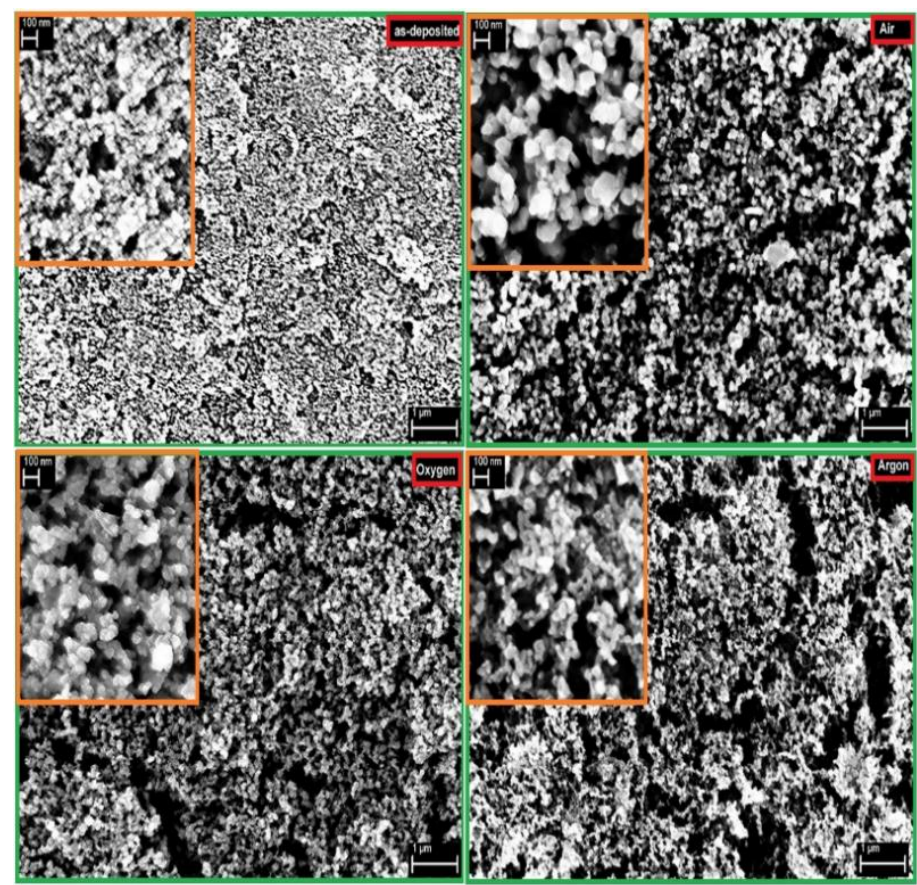

Figure 8. FESEM images of the as-deposited and $\mathrm{CuO}$ films annealed under air, oxygen, and argon at $30 \mathrm{kX}$ magnification (inset figures shows $100 \mathrm{kX}$ magnification)

\subsection{Optical Characterization}

The optical properties of the films were investigated to determine the effect of the oxidation medium on the properties of $\mathrm{CuO}$ films such as optical transmittance, band gap and Urbach energies. The transmittance spectra of the $\mathrm{CuO}$ films were taken in the wavelength range of $300-1100 \mathrm{~nm}$ at room temperature and it is given Fig 9. It was determined that changes in the oxidation of $\mathrm{CuO}$ films caused significant effects on the transmittance values. In the visible region; the transmittance values of oxidized films in air and oxygen were found to $\sim 10$ and $20 \%$ respectively, while this value was $\sim 45 \%$ for oxidized films in argon. The oxidized films in air and oxygen mediums are black and dark brown in color on visual observation, respectively while the oxidized film in argon has brownish color having relatively higher transmittance (Fig. 2). The increase in transmittance and change in color may be attributed to the formation of melanothallite which is green and transparent in thin fragments (Pankov vd., 1975).

In addition, impurities that settle in the grain gaps during the storage of the film may be cleaned from the surface in oxygen and 
argon medium. This case may have reduced the scattering on the surface and increased the transmittance values. We can see from Fig. 9 that the absorption edge has been changed for different oxidized mediums. Oxidation in the oxygen and argon medium caused deformation and defects on the band edges of the $\mathrm{CuO}$ films. Especially in argon medium, this deformation is more than others. This means that the film crystalline level in the argon medium decreased and different phases formed. This conclusion supports the XRD results.

The absorption coefficient dependence on photon energy in the spectral range of the near band-edge empirically explains the exponential law (Urbach tail). Urbach tail can be calculated by the following equation (Urbach, 1953):

$\alpha(h v)=\alpha_{0} \exp \left(h v / E_{\mathrm{u}}\right)$

where $\alpha_{0}$ is a constant, $\mathrm{E}_{\mathrm{u}}$ is Urbach energy which corresponds to the width of the band tail and could be determined as the width of the localized states (Chrzanowski vd., 1989; Anthony vd., 1997). In this study, we calculated Urbach energy values using the variation of $\ln \alpha$ vs. photon energy graphics and presented Fig. 10 and listed Table 2. From Table 2, we notice that the width of Urbach tail is high in the presence of oxygen. On the other hand, Urbach tail is minimum in a deficiency of oxygen. This is most probably due to the increase of disorder in film oxidized in air and oxygen. The steepness parameter, $\sigma=k T / E_{u}$ which characterizes the broadening of the optical absorption edge due to electronphonon or exciton-phonon interactions (Akaltun, 2015) was also determined taking $\mathrm{T}=300 \mathrm{~K}$ and given in Table 2

Figure 9. The transmittance spectra of the $\mathrm{CuO}$ films

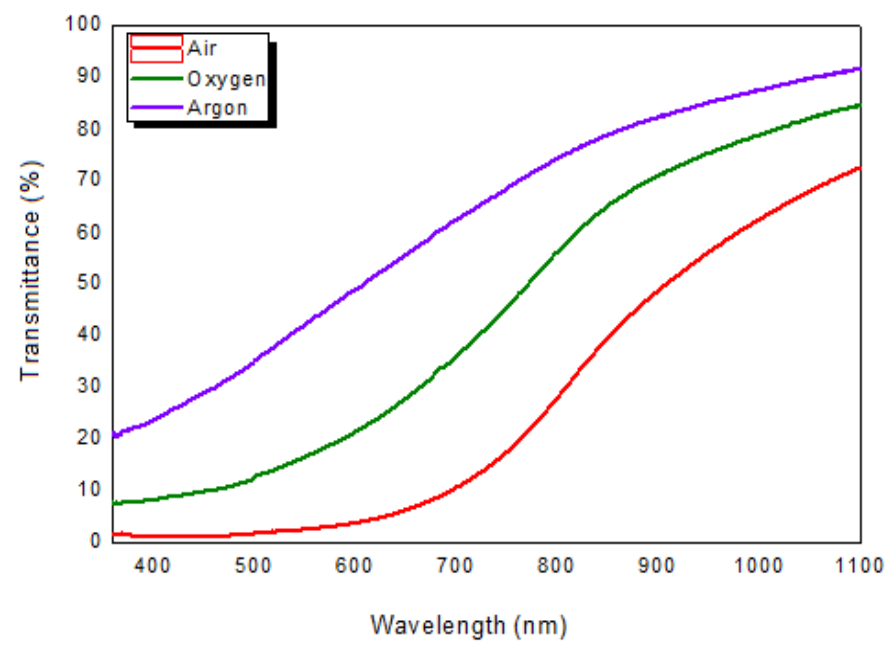

Table 2. The thickness, band gap energy, Urbach energy, refractive index and steepness parameter of $\mathrm{CuO}$ films

The band gap of $\mathrm{CuO}$ films was calculated using the optical

\begin{tabular}{c|c|c|c|c|c}
\hline $\begin{array}{c}\text { Oxidation } \\
\text { Medium }\end{array}$ & $\begin{array}{c}\mathbf{T} \\
(\mathbf{n m})\end{array}$ & $\begin{array}{c}\mathbf{E}_{\mathbf{g}} \\
(\mathbf{e V})\end{array}$ & $\begin{array}{c}\mathbf{E}_{\mathbf{u}} \\
(\mathbf{m e V})\end{array}$ & $\mathbf{n}$ & $\begin{array}{c}\boldsymbol{\sigma} \times \mathbf{1 0} \\
\boldsymbol{- 4}\end{array}$ \\
\hline Air & 68 & 1.80 & 115 & 2.94 & 2.26 \\
\hline Oxygen & 75 & 1.95 & 136 & 2.79 & 1.91 \\
\hline Argon & 62 & 2.11 & 199 & 2.66 & 2.63 \\
\hline
\end{tabular}

method. The variation of absorption coefficient $(\alpha)$ with respect to photon energy $(h v)$ was found to comply with the relation (Mageshwari vd., 2013):

$\alpha h v=A\left(h v-E_{g}\right)^{1 / 2}$

For the allowed direct transition, $A$ is the edge width parameter and $E_{g}$ is the optical band gap. The band gap values are calculated by extrapolating the linear portion of the plots of $(\alpha h v)^{2}$ vs. $h v$ have been produced, from which a direct band gap was found by extrapolating the linear portion of the curve to $(\alpha h v)^{2}=$ 0 as seen in Fig.11.

As seen in Table 2, the band gap values of $\mathrm{CuO}$ films that were oxidized in the air was $1.80 \mathrm{eV}$, and with oxidation oxygen and argon of films these values were determined to be $1.95 \mathrm{eV}$ and $2.11 \mathrm{eV}$, respectively. Similar results were obtained in different studies (Çavuşoğlu vd., 2019; Zgaira vd., 2019; Daoudi vd., 2019; Bayansal vd., 2014).

The band gap value of the oxidized film in argon has higher than others which may be attributed to the formation of melanothallite phase and chancing of band structure. The calculated band gap energies are higher as compared to the band gap energy of bulk $\mathrm{CuO}(1.2 \mathrm{eV})$. This can be attributed to improvements in the crystallinity, morphological changes, changes of atomic distances and the grain size with increasing film thickness. Additionally, as the film thickness decreases, the localized states in the band structure may merge with the band edges, resulting in the enhancement of the band gap. These results are in agreement with the literature (Boubaker vd., 2011; Ftericha vd., 2016). Also, the change in band gap and Urbach energy values were given in Fig. 12.

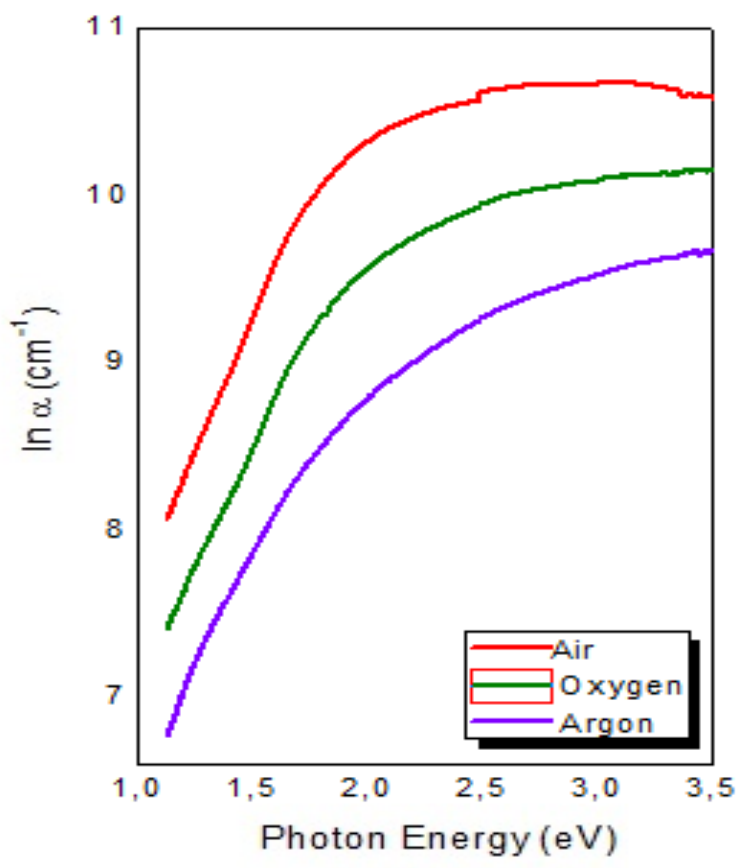

Figure 10. The Urbach plots of the CuO films 


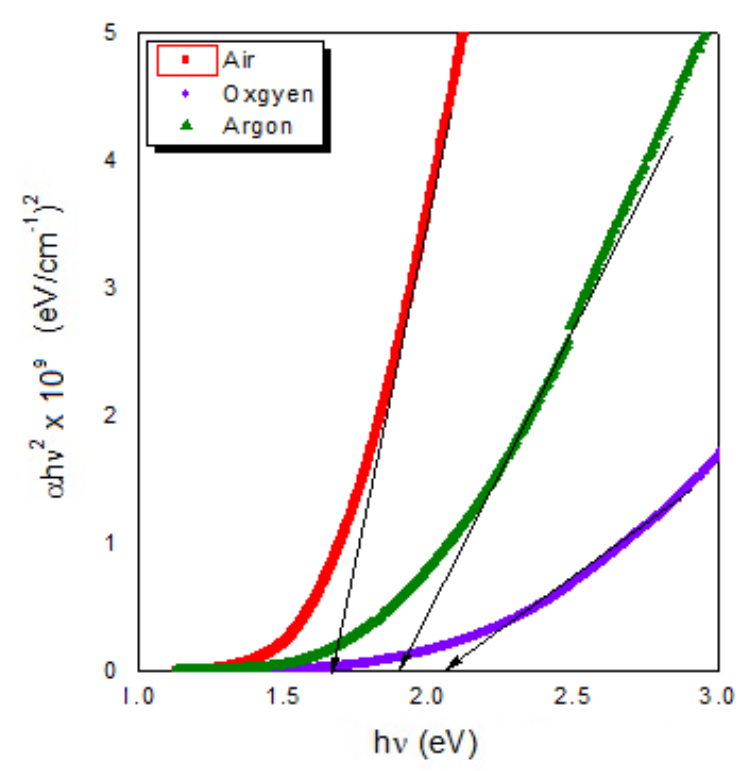

Figure 11. The plot of $(\alpha h v)^{2}$ versus $h v$ for $\mathrm{CuO}$ films

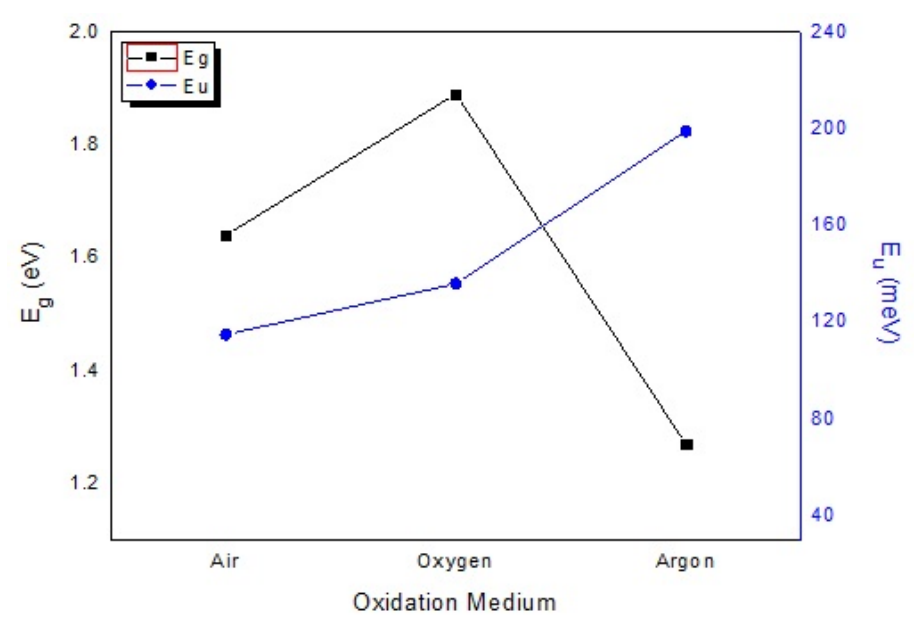

Figure 12. The band gap and Urbach energy values of $\mathrm{CuO}$ films as a function of oxidation medium

\section{Conclusions and Recommendations}

$\mathrm{CuO}$ films were successfully deposited by SILAR method. The deposited films were oxidized at $400^{\circ} \mathrm{C}$ for $2 \mathrm{~h}$ in air, oxygen, and argon separately. The effect of the oxidation medium on the structural, morphological and optical properties of the films was investigated. The analysis of XRD patterns revealed that monoclinic $\mathrm{CuO}$ phase was obtained in three different oxidation mediums while melanothallite phase with orthorhombic structure formed as a result of oxidation in argon medium. According to FESEM images, the particles on the surface were similar and large as a result of oxidation in the air and oxidant medium, while the particles were smaller in the oxidation in the argon medium and the gaps between the surface accumulations became evident. It was found that the $\mathrm{CuO}$ films oxidized under air and oxygen mediums were exhibited low transmittance (average $15 \%$ ) whereas an increase was seen in the transmittance $(45 \%)$ for the e-ISSN: 2148-2683 film oxidized in argon. It was determined that band gap values increased with the change of the oxidation medium. The lowest band gap was found as $1.80 \mathrm{eV}$ by oxidation in the air medium, while the highest band gap was formed in argon medium as 2.11 $\mathrm{eV}$. Also, the refractive index values of the films in the visible region decreased depending on the oxidation medium from 2.94 to 2.66. Raman spectroscopy sustains the $\mathrm{CuO}$ phase formation resulting from oxidation, which is also seen in XRD results.

As a result, this study showed that the oxidation medium is important in the formation of $\mathrm{CuO}$ films produced by the SILAR method and that it significantly affects the physical properties of the films. Besides, it has been demonstrated that oxidation of $\mathrm{CuO}$ films in different mediums can provide different properties to films and these films can be suitable for different applications. Especially, the $\mathrm{CuO}$ oxidized under argon medium can be used antiferromagnetic applications due to having melanothallite phase.

\section{Acknowledge}

This work was partially supported by the Çankırı Karatekin University Research Foundation (Project No. FF12035B17). Besides, authors are thankful to Prof. Dr. Evren TURAN and her doctoral students, Eskişehir Technical University, Eskişehir, Turkey, for providing the facilities of characterization.

\section{References}

Johan, M. R., Mohd Suan, M. S., Hawari, N. L., Ching, H. A. (2011). Annealing Effects on the Properties of Copper Oxide Thin Films Prepared by Chemical Deposition. International Journal of Electrochemical Science, (6), 6094-6104.

Serin, N., Serin, T., Horzum, S., Çelik, Y. (2005). Annealing Effects on the properties of copper oxide thin films prepared by shemical Deposition. Semiconductor and Science Technology, (20), 398-401.

Akgül, F. A., Akgül, G., Yıldırım, N., Ünalan, H. E., Turan, R. (2014). Influence of Thermal Annealing on Microstructural, Morphological, Optical Properties and Surface Electronic Structure of Copper Oxide Thin Films. Material Chemistry and Physics, (147), 987-995.

Ahmad, R., Tripathy, N., Hahn, Y. B., Umar, A., Ibrahim, A. A., Kim S. H., Robust, A. (2015). Enzymeless Glucose Sensor Based on $\mathrm{CuO}$ Nanoseed Modified Electrodes. Dalton Transactions, (44), 12488-12492.

Sangwaranatee, N., Horprathum, M., Chananonnawathorn, C. (2018). Effect of Annealing Treatment on Sputtered Copper Oxide Thin Film. Materials Today: Proceedings, (5), 1517015173.

Verma, M. K., Gupta, V. (2012). A Highly Sensitive $\mathrm{SnO}_{2}-\mathrm{CuO}$ Multilayered Sensor Structure for Detection of $\mathrm{H}_{2} \mathrm{~S}$ Gas. Sensors and Actuators B: Chemical, (166), 378-385.

Zou, H., Chen, S., Liu, Z., Lin, W. (2011). Selective CO Oxidation Over $\mathrm{CuO}-\mathrm{CeO}_{2}$ Catalysts Doped with Transition Metal Oxides. Powder Technology, (207), 238-244.

Umar, A., Rahman M. M., Al-Hajry, A., Hahn Y. B. (2009). MgO Polyhedral Nanocages and Nanocrystals Based Glucose 
Biosensor. Electrochemistry Communications Electrochemistry Communications, (11), 278-281.

Kumar, K., Suresh. S., Murugesan, S., Raj, S. (2013). CuO Thin Films Made of Nanofibers for Solar Selective Absorber Applications. Solar Energy, (94), 299-304.

Heng, B., Qing, C., Wang, H., Sun, D., Wang, Tang, Y. (2015). Facile Synthesis of Fe-Incorporated $\mathrm{CuO}$ Nanoarrays with Enhanced Electrochemical Performance for Lithium Ion Full Batteries. Journal of Alloys and Compounds, (649), 899-905.

Bednorz, J. G., Müller, K. A. (1986). Possible High Tc Superconductivity in the Ba-La-Cu-O System. Zeitschrift für Physik B Condensed Matter, (64), 189-193.

Itoh, T. and Maki, K. (2007). Growth Process of $\mathrm{CuO}\left(\begin{array}{lll}1 & 1 & 1\end{array}\right)$ and $\mathrm{Cu}_{2} \mathrm{O}\left(\begin{array}{lll}0 & 0 & 1\end{array}\right)$ Thin Films on $\mathrm{MgO}\left(\begin{array}{lll}0 & 0 & 1\end{array}\right)$ Substrate Under Metal-Mode Condition by Reactive DC-Magnetron Sputtering. Vacuum, (81), 1068-76.

Mukherjee, N., Show, B., Maji, S. K., Madhu, U., Bhar, S. K., Mitra, B. ,C., Khan, G.G., Mondal, A. (2011). CuO NanoWhiskers: Electrodeposition, Raman Analysis, Photoluminescence Study and Photocatalytic Activity. Material Letters, (65), 3248-50.

Jin, C., Kim, H., An, S., Lee, C. (2012). Highly Sensitive $\mathrm{H}_{2} \mathrm{~S}$ Gas Sensors Based on CuO-Coated $\mathrm{ZnSnO}_{3}$ Nanorods Synthesized by Thermal Evaporation. Ceramics International, (38), 5973-78.

Koh, T., O’Hara, E., Gordon, M. J. (2013). Growth of nanostructured $\mathrm{CuO}$ thin films via microplasma-assisted, reactive chemical vapor deposition at high pressures. Journal of Crystralline Growth, (363). 69-75.

Qin, H., Zhang, Z., Liu, X., Zhang, Y., Hu, J. (2010). RoomTemperature Ferromagnetism in $\mathrm{CuO}$ Sol-Gel Powders and Films. Journal of Magnetism and Magnetic Materials, (322), 1994-1998.

Bayansal, F., Çetinkara H. A., Kahraman, S., Cakmak, H. M., Güder H. S. (2012). Nano-Structured CuO Films Prepared by Simple Solution Methods: Plate-like, Needle-likeand Network-Like Architectures. Ceramics Intirnational, (38), 1859-66.

Halin, D. S. C., Talib, I. A., Daud, A. R., Hamid, M. A. A. (2014). Effect of Annealing Atmosphere on the Morphology of Copper Oxide Thin Films Deposited on $\mathrm{TiO}_{2}$ Substrates Prepared by Sol-Gel Process. Key Engineering Materials, (594), 113-117.

Bayansal, F., Taşköprü, T., Şahin, B., Çetinkara, H. A. (2014). Effect of Cobalt Doping on Nanostructured CuO Thin Films. Metallurgical and Materials Transactions A, (45), 36703674.

Saad, H. B., Ajili, M., Dabbabi, S., Kamoun, N. T. (2020). Investigation on Thickness and Annealing Effects on Physical Properties and Electrical Circuit Model of CuO Sprayed Thin Films. Superlattices and Microstructures, (142), 106508.

Özaslan, D., Erken, O., Güneş, M., Gümüş, C. (2020). The Effect of Annealing Temperature on the Physical Properties of $\mathrm{Cu}_{2} \mathrm{O}$ Thin Film Deposited by SILAR Method. Physica B: Physics of Condensed Matter, (580), 411922.

Singh, R., Yadav, L., Tripath. S. (2019). Effect of Annealing Time on The Structural and Optical Properties of n-CuO Thin films Deposited by Sol-Gel Spin Coating Technique and Its Application in n-CuO/p-Si Heterojunction Diode. Thin Solid Films, (685), 195-203.

Shevko, V., Lavrov, B., Serzhanov, G., Badikova, A., Uteeva, R. (2015). Chlorination of Atacamite. Industrial Technology and Engineering, (3-16), 84-91.
Gençy1lmaz, O., Taşköprü, T. (2017). Effect of pH on the Synthesis of CuO Films by SILAR Method. Journal of Alloys and Compounds, (695), 1205-1212.

Zamfirescu, C., Dinçer, İ., Naterer, G. F. (2010). Thermophysical Properties of Copper Compounds in Copper-Chlorine Thermochemical Water Splitting Cycles. International Journal of Hydrogen Energy, (35), 4839-4852.

Pankove, J. I. (1975). Optical Processes in Semiconductors. Dover, New York.

Chrzanowski, J., Irwin, J.C. (1989). Raman Scattering from Cupric Oxide. Solid State Communications, (70), 11-14.

Anthony, J. W. (1997). Handbook of Mineralogy, Halides, Hydroxides, Oxides. Mineral Data Publishing.

Urbach, F. (1953). The Long-Wavelength Edge of Photographic Sensitivity and of the Electronic Absorption of Solids. Physical Review, (92), 1324.

Boubaker, K. (2011). Atomic Structures Beyond the Spherical Approximation Along with PNC as Conjectured Explanations to Urbach Tailing in Neutral İsolated Ytterbium. The European Physical Journal B, (84), 235-239.

Ftericha, M., Nasra, F. B., Lefia, R., Toumib M., Guermazi S. (2016). Effect of Concentration of Hexamethylenetetramine in Structure, Microstructure and Optical Properties of $\mathrm{CuO}$ Nanoparticles Synthesized by Hydrotermal Route. Materials Science in Semiconductor Processing, (43), 114-122.

Mahr, H. (1962). Ultraviolet Absorption of KI Diluted in KCL Crystals. Physical Review, (125), 1510.

Mageshwari, K., Sathyamoorthy R. (2013). Physical Properties of Nanocrystalline $\mathrm{CuO}$ Thin Films Prepared by the SILAR Method. Material Science and Semiconductor Processing, (16), 337-343.

Akaltun, Y. (2015). Effect of Thickness on the Structural and Optical Properties of $\mathrm{CuO}$ Thin Films Grown by Successive Ionic Layer Adsorption and Reaction. Thin Solid Films, (594), 30-34.

Centi, G., Trifiro, F. (1989). Studies in Surface Science and Catalysis, Italy, 55.

Dhaouadi, M., Jlassi, M., Sta, I., Miled, I. B., Mousdis, G., Kompitsas, M., Dimassi, W. (2019). Influence of Pd-Doping on Structural, Morphological, Optical and Electrical Properties of Sol-Gel Derived CuO Thin Films. Surfaces and Interfaces, (17), 100352.

Moumen, A., Hartiti, B., Comini, E., Khalidi Z. E., Munasinghe, H. M. M., Fadili, S., Thevenin, P. (2019). Preparation and Characterization of Nanostructured $\mathrm{CuO}$ Thin films Using Spray Pyrolysis Technique. Superlattices and Microstructures, (127), 2-10.

Djebian, R., Boudjema, B., Kabir, A., Sedrati, C. (2020). Physical Characterization of $\mathrm{CuO}$ Thin Films Obtained by Thermal Oxidation of Vacuum Evaporated Cu. Solid State Science, (101), 106147.

Yuksel, M., Pennings, J. R., Bayansal, F., Yeow, John T.W. (2020). Effect of B-Doping On the Morphological, Structural and Optical Properties of SILAR Deposited CuO Films, Physica B: Physics of Condensed Matter, (599), 412578.

Çavuşoğu, H., Aydın, R. (2019). Complexing Agent Triethanolamine Mediated Synthesis of Nanocrystalline $\mathrm{CuO}$ Thin Films at Room Temperature via SILAR Technique. Superlattices and microstructures, (128), 37-37.

Zgaira, I. A., Omran Alkhayatta, A. H., Muhmooda, A. A., Hussain, S. K. (2019). Investigation of Structure, Optical and Photoluminescence Characteristics of $\mathrm{Li}$ Doped $\mathrm{CuO}$ 
Nanostructure Thin Films Synthesized by SILAR Method. Optik, (91), 48-54.

Daoudi, O., Qachaou, Y., Raidou, A., Nouneh, K., Lharch, M., Fahoume, M. (2019). Study of the Physical Properties of $\mathrm{CuO}$ Thin Films Grown by Modified SILAR Method for Solar Cells Applications. Superlattices and microstructures, (127), 93-99.

Bayansal, F., Şahin, B., Yüksel, M., Çetinkara H. A. (2014). Modification of Morphological, Structural and Optical Properties of SILAR-Based Growth of CuO Films on GlassSlides by Addition of Dextrin. Journal of Alloys and Compounds, (614), 379-382.

Peng, W., Zhou, Y., Li, J., Liu, Y., Zhang, J., Xiang, G., Zhu, X., Li, R., Wang, H., Zhao, Y. (2021). Annealing Temperature Induced Physical Characteristics of $\mathrm{CuO}$ Films Grown by Magnetron Sputtering. Materials Science in Semiconductor Processing, (131), 105883. 